\title{
Comunicação low-cost. desinvestimento ou fórmula de sucesso?
}

Carla Pereira*, António Azevedo** e Teresa Ruão***

Resumo: O termo low-cost invadiu o nosso quotidiano. Começou com as companhias de aviação, mas rapidamente se estendeu às telecomunicações, à moda, aos hotéis, aos automóveis, e o conceito não pára de se replicar. Particularmente numa conjuntura económica desfavorável como a que atravessamos, os consumidores estão mais sensíveis ao preço e há empresas que respondem com cortes nos seus custos para oferecerem soluções mais baratas. Mas a "democratização" que este conceito permite e a globalização a que assistimos talvez sejam uma ilusão. Com este trabalho pretendemos contribuir para o estudo do mercado português da comunicação, analisando a forma de actuação das agências nacionais.

Nesse sentido, propomo-nos reflectir sobre o conceito low-cost no mercado da comunicação, a filosofia das agências que adoptam este posicionamento, o tipo de serviço prestado e de que forma sustentam a sua vantagem competitiva. Com o presente estudo empírico, consultámos as microempresas e PME nacionais para percebermos a receptividade das empresas portuguesas às agências de comunicação low-cost.

Desta forma, procuraremos concluir se em Portugal comunicação low-cost é sinónimo de desinvestimento ou uma fórmula de sucesso.

Palavras-chave: low-cost; agências; relação agência-cliente; posicionamento; comunicação; vantagem competitiva; criatividade.

\section{Introdução}

O termo low-cost invadiu o nosso quotidiano. Começou com as companhias de aviação, mas rapidamente se estendeu às telecomunicações, à moda, aos hotéis, aos automóveis e o conceito não pára de se replicar. Tudo começou em 1966, quando Rollin King

* Universidade do Minho (carlaavintes@gmail.com).

** Universidade do Minho (antonioa@eeg.uminho.pt).

*** Instituto de Ciências Sociais da Universidade do Minho, Centro de Estudos Comunicação e Sociedade (truao@ics.uminho.pt). 
contactou um amigo para criar uma companhia aérea de baixo custo que, nos Estados Unidos da América, ligasse as três principais cidades do Texas: Dallas, San Antonio e Houston. Esta visão, também identificada como "Efeito Southwest", permitiu a criação de uma "companhia aérea do povo" e simultaneamente assinalava o aparecimento do conceito low-cost.

Alguns especialistas defendem que há espaço para o low-cost se estender a outros sectores de actividade e, em Portugal, o termo também tem vindo a ganhar terreno em diversos sectores - moda, hotelaria, telecomunicações, aviação, automóveis. Também assistimos, no nosso país, ao aparecimento de agências de comunicação que afirmam este posicionamento, e é precisamente nesta dialéctica que se impõe um estudo para análise e reflexão sobre o conceito low-cost no domínio da comunicação.

\section{Objectivos da pesquisa}

Com este trabalho pretendemos contribuir para o estudo do mercado português da comunicação, analisando a forma de actuação das agências low-cost nacionais. Nesse sentido, propomo-nos reflectir sobre a filosofia que as rege, o tipo de serviço prestado e de que forma sustentam a sua vantagem competitiva. Pretendemos ainda perceber o comportamento de compra das empresas portuguesas, reflectindo sobre a oferta existente em termos de serviços de comunicação.

Esta temática coloca-nos várias inquietações, a saber:

- Qual a importância que as empresas, em particular as PME, atribuem à comunicação?

- Será que o conceito de comunicação low-cost é apelativo para as empresas?

- Que tipo de serviço preconizam as agências que se posicionam como sendo de low-cost?

- Que critérios utilizam para encurtar os custos?

- Que imagem transmitem para o mercado?

- Assistiremos, no campo da comunicação, a uma réplica dos perfis que caracterizam os consumidores adeptos de baixos custos noutras áreas?

- Quais as expectativas das empresas/responsáveis de comunicação das empresas quando recorrem aos serviços de uma agência de comunicação low-cost?

- Como as vêem as empresas? Como sinónimo de criatividade e formas alternativas de comunicar ou como uma solução na qual o preço é a mais-valia?

- A conjuntura económica desfavorável dita novas regras?

- Será caso para dizer que, em Portugal, estamos perante uma florescente comunicação low-cost? Ou o barato sai caro?

- O mercado está “sintonizado” ou será necessário que as agências de comunicação repensem a sua estratégia/oferta?

O objectivo desta pesquisa será lançar as sementes para a construção de um modelo teórico que permita analisar a comunicação em Portugal, de forma a perceber se, no 
nosso país, estamos a assistir ao emergir de uma tendência que poderemos designar como comunicação low-cost. O que a move e como se organiza? O objectivo será concluir se a comunicação low-cost em Portugal é sinónimo de desinvestimento ou uma fórmula de sucesso.

\section{Contextualização}

No contexto de crise mundial em que este trabalho foi desenvolvido, existem marcas internacionais a divulgarem cortes orçamentais nas verbas dedicadas ao marketing e a procurarem estratégias funcionais mais baratas: é o caso da Renault (Saint-Seine, 2007). No mercado interno, assiste-se a uma diminuição do consumo por parte dos consumidores portugueses, já que Portugal é o país que tem mais dificuldades em fazer face às despesas mensais (Lima, 2009). E Berman et al. (2009: 29) defendem que os próximos cinco anos vão trazer mais mudança para a indústria da publicidade do que os últimos cinquenta.

A actual conjuntura obriga as agências a um acompanhamento mais próximo e aprofundado dos meios e das estratégias de comunicação que propõem aos seus clientes, uma vez que a recessão económica levou muitas empresas a cortarem nos custos e as áreas da publicidade e comunicação são das mais afectadas. Conscientes desta problemática, algumas agências aproveitam para afirmar o seu posicionamento low- cost e outras para criar soluções de baixo custo. Dos packs de marketing integrado à publicidade em novos suportes ou às acções de comunicação low-cost, há de tudo um pouco no mercado.

Yuksel e Sutton-Brady (2007) mostraram que um dos principais factores que levam as empresas a iniciarem uma nova relação com uma agência prende-se com a situação financeira da empresa. Já Wackman et al. (cit. in Waller, 2004) demonstraram que o factor mais importante para a durabilidade do trabalho entre um cliente e uma agência é o tipo de relacionamento que mantêm, seguido dos factores organizacionais, modelos de trabalho e, finalmente, o trabalho produzido. Os factores determinantes para a selecção, manutenção e rompimento da relação entre as agências e os clientes são aspectos fundamentais deste trabalho, na medida em que, através do estudo empírico que realizámos, procurámos aferir quais os factores e serviços que as empresas portuguesas mais valorizam nas agências. O objectivo é perceber se ambas as partes estão conscientes e alinhadas quanto ao seu papel em todo este processo. Estas questões são fundamentais para serem posteriormente confrontadas com os resultados obtidos no inquérito a realizar por questionário e que procurará perceber se o conceito low-cost na comunicação é um argumento importante quando uma empresa se encontra a seleccionar a agência com a qual vai trabalhar.

Os estudos consultados demonstram que, no desenvolvimento de uma campanha, existe uma relação entre o risco e a criatividade. El-Murad e West (2003) demonstraram que, quanto maior o risco, mais criativa se torna a publicidade e que os clientes mais pequenos são mais receptivos ao risco. Será a criatividade um dos factores mais valorizados pelas empresas nacionais? 
$\mathrm{E}$ as agências portuguesas correspondem aos anseios dos seus clientes ou terão de repensar as suas estratégias, ofertas e posicionamentos? "W. Chan Kim e Renée Mauborgne explicam que, para alcançar o êxito na produção de valor inovativo, as empresas só têm duas possibilidades: diversificar a oferta e produzir low-cost" (Gaggi e Narduzzi, 2006: 34-35). A primeira parece-nos consensual; será a segunda uma chave para o sucesso? É o que procuraremos concluir no final deste trabalho.

\section{O conceito low-cost}

Um dos factores que contribuiu para que o conceito low-cost se espalhasse para lá da indústria da aviação foram as novas tecnologias e as infinitas possibilidades que estas proporcionam. Importa referir que o conceito low-cost aplicado a uma área intangível como é a comunicação não deixa de ter como principal objectivo a criação de novos públicos e transforma o modo de as agências conquistarem os clientes. Assim, importa conhecer a permeabilidade das empresas portuguesas a aceitar os desafios que as agências de comunicação apresentam através do conceito low-cost.

Os meios de comunicação usados para divulgação das agências low-cost e os suportes de comunicação que estas sugerem aos seus clientes (meios tradicionais/novos meios) são critérios que fazem a diferença. Para soluções económicas ao nível da comunicação, também contribuem as empresas que actuam a montante e a jusante das agências, nomeadamente bancos de imagens, centrais de compras, empresas gráficas, de produção audiovisual e de tecnologias da informação.

$\mathrm{Na}$ actual conjuntura global de crise, há agências que investem no lançamento de marcas que apresentam soluções low-cost, como a Novologo; outras propõem aos clientes a utilização de novas formas de comunicação. Neste domínio, os serviços de assessoria de imprensa - que vinculam o produto ou o serviço que vendem com a actualidade informativa - são um dos exemplos de serviço promovidos por agências com posicionamento low-cost, como a Hotshop ou a Ric \& Vier.

Em Portugal as agências de comunicação com posicionamento low-cost apresentam aos clientes soluções baratas, comparativamente com propostas apresentadas num passado não muito longínquo ou pelas agências concorrentes. Tendencialmente este tipo de agência opta por apresentar apenas uma proposta criativa, aparentemente com qualidade equiparada à das agências tradicionais mas com custos mais reduzidos. Para garantir estes preços, as agências recorrem, em grande medida, às tecnologias de informação e de comunicação e optam por recursos humanos mais polivalentes, uma vez que procuram trabalhar com uma equipa de colaboradores seniores ou têm uma rede de freelancers na retaguarda. A escolha de instalações mais pequenas, normalmente situadas em zonas periféricas das grandes cidades, é outra forma de encurtarem as despesas para garantir o posicionamento low-cost.

Os consumidores estão a alterar os seus comportamentos de compra como resultado da crise económica que se vive no presente (Lima, 2009). Gaggi e Narduzzi (2006: 65) defendem que "o cliente low-cost é nómada, no sentido em que se predispõe facilmente a mudar de fornecedor se e quando disso retirar vantagens, interessado principalmente 
em repartir pelo maior número possível de bens e serviços o rendimento de que dispõe para as suas compras. É um consumidor mais ou menos exclusivamente interessado no binómio preço-teor prático do consumo”.

Será que o preço "justo” para os clientes é sustentável para as empresas nacionais? Em Portugal temos um mercado muito fragmentado e com excesso de oferta. A precariedade das condições de trabalho dos profissionais da comunicação em Portugal será a solução para garantir a subsistência do sector?

A monitorização das campanhas, por exemplo, é um serviço que normalmente não é proposto pelas agências low-cost, mas não será este um factor fundamental para as empresas-cliente, principalmente numa conjuntura de crise, na qual os budgets são contados ao tostão? Não será essa uma fragilidade das agências low-cost? Como defendem Gaggi e Narduzzi (2006: 147), “devemos aprender com o mesmo espírito de inovação a explorar em escala mundial a capacidade criadora que possa activar tendências - desta vez, não 'exclusivas', mas 'inclusivas' - de consumo low-cost”.

Este conceito terá (ou manterá) sucesso com a retoma ou o low-cost tem os dias contados? Que futuro se perspectiva para a comunicação low-cost?

\section{Design metodológico}

O design metodológico que adoptámos procura apurar as semelhanças e diferenças entre a forma como os grandes anunciantes e as PME organizam e vêem a comunicação. Para nos certificarmos da consistência do nosso trabalho e da adequação do questionário à realidade, numa primeira fase - que decorreu entre Maio e Setembro de 2009 - optámos por realizar entrevistas em profundidade a uma amostra de seis directores de Comunicação e Marketing de algumas das principais empresas anunciantes existentes em Portugal. Para tal, recorremos às empresas que integram a Associação Portuguesa de Anunciantes (APAN), de forma a percebermos quais os critérios que estes gestores adoptam para selecção dos seus parceiros de comunicação. O objectivo era percebermos de que forma os anunciantes nacionais gerem os seus investimentos em marketing e comunicação. Para tal, elaborámos um guião - disponível no Apêndice 1 - com os tópicos a abordar na entrevista. A organização dos departamentos de marketing e/ou comunicação na empresa e os meios a eles afectos, os budgets disponíveis e a sua distribuição pelos diferentes meios, a relação com as agências, o tipo de contrato existente e os factores mais valorizados para selecção/mudança de agência foram alguns dos aspectos abordados. Além destes, procurámos perceber que avaliação os nossos interlocutores fazem do mercado da comunicação em Portugal e a sua permeabilidade ao conceito de comunicação low-cost.

Através destas entrevistas procurámos seleccionar as dimensões a analisar através de um inquérito que foi administrado a microempresas e PME nacionais.

Depois, seguiu-se a construção do questionário e o pré-teste - em Setembro de 2009 - realizado através de auscultação da opinião de quatro responsáveis de marketing de empresas nacionais.

Inicialmente o questionário foi elaborado, impresso e administrado no Congresso Internacional de PME, promovido pela Associação Nacional de PME, que teve lugar no 
Hotel D. Pedro, em Lisboa, no dia 10 de Outubro de 2009. Face à fraca afluência ao congresso, que inviabilizou a recolha de questionários suficientes para a nossa amostra, realizámos um questionário electrónico dirigido a microempresas e PME nacionais. Para tal, fizemos chegar o questionário à Associação Nacional das PME para divulgação pelos seus associados. O questionário foi enviado por e-mail, com uma sintética explicação a enquadrar a pesquisa que estava a ser realizada. Paralelamente, e face à falta de resposta da associação, procedemos ao envio do questionário em formato electrónico (e-mail com um link para preenchimento do questionário) para uma base de dados com cerca de três mil contactos de empresas.

Restringimos a nossa amostra ao universo das microempresas e PME, informando no e-mail de divulgação do questionário - enviado durante o mês de Dezembro - que o mesmo se destinava a este tipo de empresas. Para definição da amostra, analisámos o tecido empresarial português no qual predominam as microempresas e PME. Segundo dados do Instituto Nacional de Estatística (INE), as microempresas e PME correspondem a 99,92\% do tecido empresarial português, o que, em termos práticos, significa que o número de grandes empresas é absolutamente residual, uma vez que não chegam a um milhar $(0,08 \%)$. O gráfico a seguir apresentado ilustra bem esta realidade.

\section{Gráfico 1. Número de empresas existentes em Portugal em 2008}
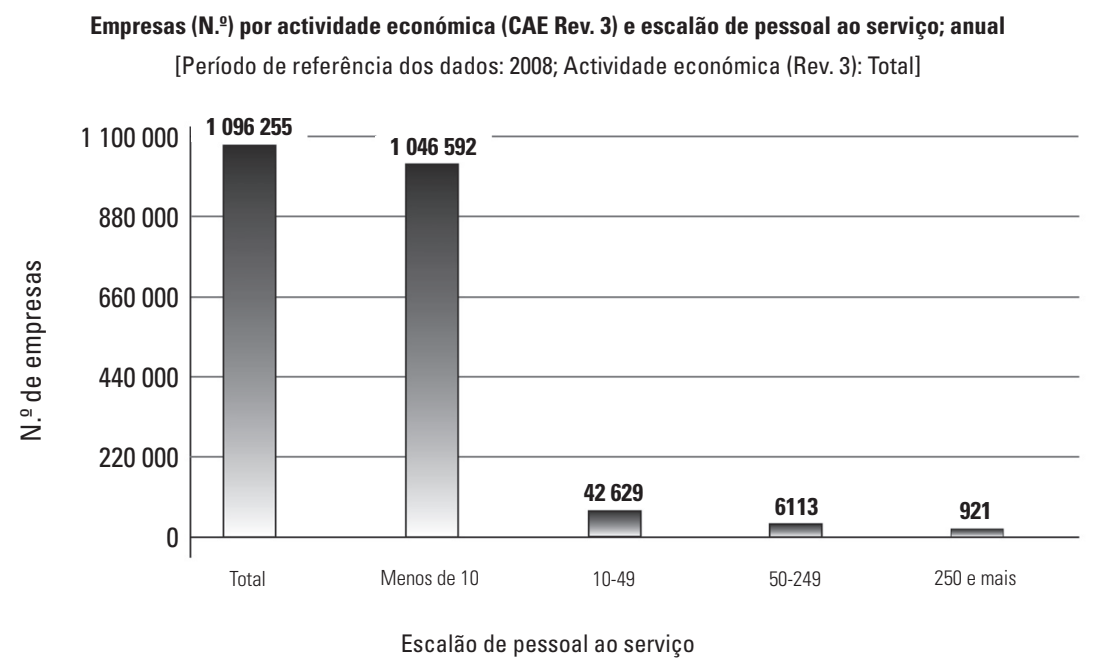

Fonte: INE (Última actualização destes dados: 17 de Março de 2010)*

* In http://www.ine.pt/xportal/xmain?xpid=INE\&xpgid=ine_indicadores\&indOcorrCod=0004041\&contexto=bd\&selTab=tab2.

A aplicação do questionário fez-se a uma amostra não aleatória feita por conveniência, na medida em que recorremos a uma base de dados com 2960 empresas a que tivemos acesso por motivos profissionais. 
O instrumento de pesquisa foi um questionário de 26 questões. Utilizámos perguntas fechadas e respostas dicotómicas, bem como perguntas de resposta múltipla, algumas delas escalares, de forma a melhor quantificar o grau de concordância face às questões apresentadas. A grande parte delas aplicámos uma escala de medição tipo Likert, de cinco pontos, que variou de “1" ("Discordo totalmente") a "5" ("Concordo totalmente").

A nossa amostra contempla 102 questionários correctamente preenchidos (foram excluídos seis por estarem incompletos), que englobam dezasseis microempresas $(15,7 \%$ das respostas), 41 pequenas empresas (40,2\% dos inquiridos) e 45 empresas médias (44,1\% dos questionários). Quanto à caracterização dos inquiridos, 28,4\% dos respondentes pertencem à administração/gerência da empresa; 25,5\% desempenham funções nas áreas de marketing e/ou comunicação, 38,2\% correspondem a outros quadros superiores e apenas $7,8 \%$ dos indivíduos desempenham outras funções que não as anteriormente descritas.

\section{Modelo teórico e hipóteses de pesquisa}

Para este estudo de cariz quantitativo, basearemos a pesquisa na relação, em hipótese, existente entre a dimensão da empresa e a apetência para a comunicação low-cost, interligando-o com a escolha dos serviços mais valorizados pelas empresas, os factores que poderão influenciar o processo de selecção de uma agência, a conjuntura económica e a imagem que associam ao conceito de comunicação low-cost.

Nesse sentido, questionámos as empresas em relação à sua forma de organização, marketing-mix, se recorrem a agências, o tipo de serviço que mais valorizam, o mix de meios e, entre outros, o conhecimento que têm do mercado da comunicação em Portugal.

O esquema seguinte ilustra o modelo teórico subjacente a este trabalho.

\section{Modelo teórico}

\section{Esquema 1. Esquema simplificado do modelo teórico subjacente ao presente estudo}

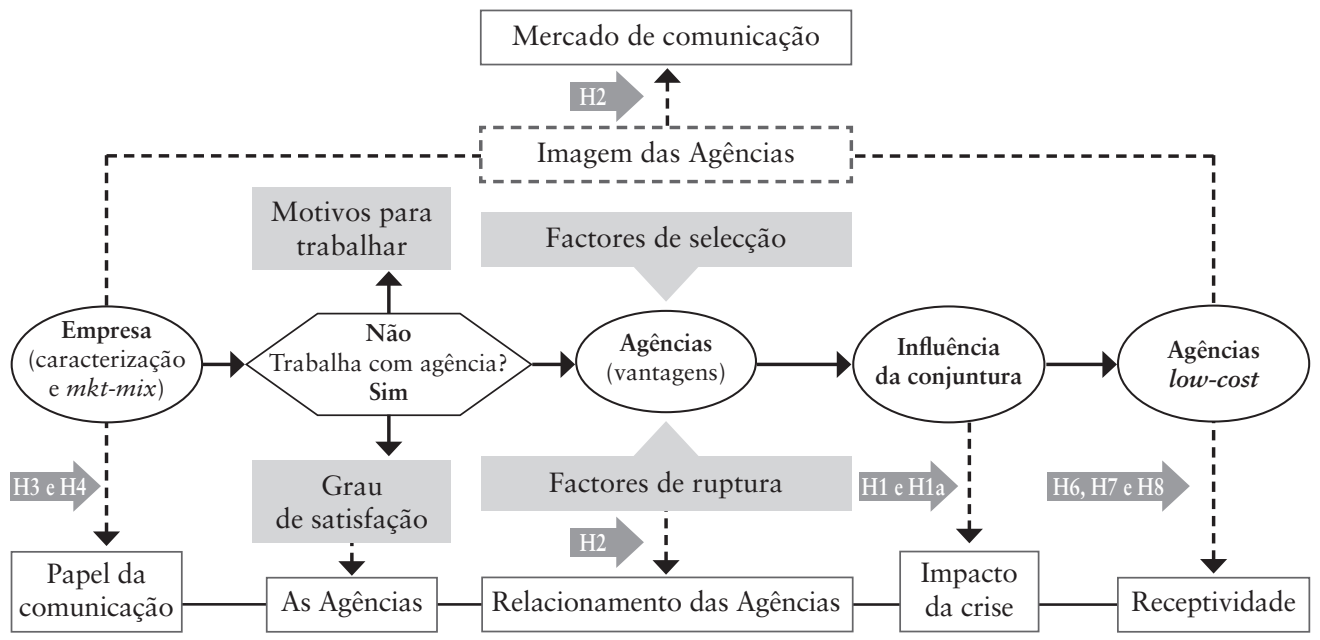


O quadro a seguir descrito sintetiza os objectivos do questionário realizado no âmbito do presente estudo.

Quadro 1. Quadro-síntese com as dimensões e hipóteses estudadas

\begin{tabular}{|c|c|c|c|}
\hline $\begin{array}{l}\text { DIMENSÕES } \\
\text { ESTUDADAS }\end{array}$ & OUTPUTS ESPERADOS & $\begin{array}{l}\text { PERGUNTAS } \\
\text { QUESTIONÁRIO }\end{array}$ & HIPÓTESES \\
\hline $\begin{array}{l}\text { Caracterização } \\
\text { das } \\
\text { microempresas } \\
\text { e PME } \\
\text { nacionais }\end{array}$ & $\begin{array}{l}\text { - Dimensão da empresa; } \\
\text { - Existência de um } \\
\text { departamento de } \\
\text { comunicação e/ou marketing; } \\
\text { - Núcleo de decisão dos } \\
\text { assuntos de comunicação. }\end{array}$ & $1,2,17$ e 18 & $\begin{array}{l}\text { H3: A existência de um } \\
\text { departamento de marketing } \\
\text { e/ou comunicação aumenta a } \\
\text { probabilidade de as empresas } \\
\text { trabalharem com agências. }\end{array}$ \\
\hline $\begin{array}{l}\text { Marketing-mix } \\
\text { da empresa }\end{array}$ & $\begin{array}{l}\text { - Orientação para o cliente; } \\
\text { - Papel da comunicação; } \\
\text { - Escolha e eficácia dos } \\
\text { meios. }\end{array}$ & $3,4,5,6,7$ e 8 & $\begin{array}{l}\text { H4: As empresas que trabalham } \\
\text { com agências têm maior } \\
\text { tendência para monitorizarem } \\
\text { as suas campanhas. }\end{array}$ \\
\hline $\begin{array}{l}\text { Selecção e } \\
\text { término da } \\
\text { relação com } \\
\text { agências }\end{array}$ & $\begin{array}{l}\text { - Factores para seleccionar } \\
\text { agência; } \\
\text { - Motivos para terminar a } \\
\text { relação de trabalho; } \\
\text { - Serviços mais valorizados. }\end{array}$ & $14,15,16$ e 19 & $\begin{array}{l}\text { H5: A localização não é um } \\
\text { factor determinante para a } \\
\text { selecção de uma agência. }\end{array}$ \\
\hline $\begin{array}{l}\text { Influência da } \\
\text { conjuntura }\end{array}$ & $\begin{array}{l}\text { - Atitude perante a crise; } \\
\text { - Papel das campanhas de } \\
\text { comunicação num cenário } \\
\text { de crise. }\end{array}$ & 11,12 e 13 & $\begin{array}{l}\text { H1: A crise altera a forma } \\
\text { como as empresas encaram } \\
\text { a comunicação e os seus } \\
\text { investimentos. } \\
\text { H1a: A crise leva as empresas a } \\
\text { cortarem nos investimentos em } \\
\text { comunicação. }\end{array}$ \\
\hline $\begin{array}{l}\text { Imagem da } \\
\text { comunicação } \\
\text { em Portugal }\end{array}$ & $\begin{array}{l}\text { - Vantagens em trabalhar } \\
\text { com agências; } \\
\text { - Opinião sobre o trabalho } \\
\text { das agências; } \\
\text { - Grau de satisfação com o } \\
\text { trabalho realizado. }\end{array}$ & $9,10,20$ e 21 & $\begin{array}{l}\text { H2: As empresas que não } \\
\text { trabalham com agências têm } \\
\text { uma imagem mais positiva do } \\
\text { mercado da comunicação, em } \\
\text { particular das agências. }\end{array}$ \\
\hline $\begin{array}{l}\text { Comunicação } \\
\text { low-cost }\end{array}$ & $\begin{array}{l}\text { - Imagem associada ao } \\
\text { conceito; } \\
\text { - Imagem das agências low- } \\
\text { cost; } \\
\text { - Elasticidade do factor } \\
\text { preço; } \\
\text { - Receptividade às agências } \\
\text { low-cost. }\end{array}$ & $\begin{array}{c}22,23,24,25 \\
\text { e } 26\end{array}$ & $\begin{array}{l}\text { H6: A conjuntura económica } \\
\text { desfavorável (crise) torna } \\
\text { as agências de comunicação } \\
\text { low-cost uma solução mais } \\
\text { apetecível para as empresas. } \\
\text { H7: As empresas que não } \\
\text { trabalham com agências têm } \\
\text { uma imagem mais positiva } \\
\text { das agências de comunicação } \\
\text { low-cost. } \\
\text { H8: As empresas que não } \\
\text { trabalham com agências estão } \\
\text { mais receptivas a trabalhar } \\
\text { com agências de comunicação } \\
\text { low-cost. }\end{array}$ \\
\hline
\end{tabular}




\section{Resultados obtidos}

Os resultados obtidos demonstram-nos que quem decide quais os investimentos a realizar em publicidade, comunicação, promoção e afins, é a administração/gerência da empresa, ou seja, as decisões que afectam a imagem e a estratégia da empresa são tomadas ao mais alto nível. Uma opinião que não se altera em função do cargo desempenhado pelo respondente.

Mais de metade dos inquiridos $(58,8 \%)$ é da opinião de que é o produto/serviço que mais contribui para vender os produtos/serviços da empresa, logo seguido do preço $(22,5 \%)$ e da comunicação $(14,7 \%)$.

O número de empresas com uma pessoa e/ou departamento responsável pelas áreas de marketing e comunicação (cerca de $70 \%$ das participantes) atesta a consciência, por parte do tecido empresarial português, da importância destas áreas. Já diz o provérbio "quem não aparece, esquece" e esta máxima é ainda mais premente num mercado cada vez mais volátil e competitivo. Contudo, e ao contrário da hipótese que equacionámos (H3) - a existência de um departamento de marketing e/ou comunicação aumenta a probabilidade de as empresas trabalharem com agências -, os resultados demonstram que este é mesmo um dos principais motivos apresentados para as empresas não trabalharem com agências.

Em termos de estudos de mercado, uma variável que introduzimos - por um lado para aferir a importância que as empresas conferem a esta ferramenta e, por outro, para tentar concluir se este tipo de serviço poderia ser uma aposta a explorar pelas agências em termos do seu portefólio de serviços - teve resultados animadores. Cerca de $60 \%$ das empresas inquiridas afirmam que realizam estudos de mercado, mas há ainda um longo caminho a percorrer em termos da sua frequência. Pelo facto, consideramos que este serviço será uma área a explorar pelas agências portuguesas. Quanto à monitorização das campanhas, é realizada em 71,6\% das empresas que participaram neste estudo. Em 51\% dos casos é assegurada pela própria empresa; 7,8\% dos inquiridos responderam que é feita por outra empresa e 9,8\% afirmam que é realizada pela empresa em conjunto com a agência. Estes resultados confirmam a hipótese 4: As empresas que trabalham com agências têm maior tendência para monitorizarem as suas campanhas. E, na nossa opinião, esta tendência surge da necessidade de avaliar o trabalho das agências e a eficácia dos investimentos realizados em comunicação.

Uma parte significativa dos inquiridos $(41,2 \%)$ considera que, para a sua empresa, a comunicação é sinónimo de um investimento necessário, e 35,3\% encaram-na como uma estratégia para ganhar notoriedade. A comunicação é vista como um meio para vender mais por $15,7 \%$ dos respondentes; como uma forma de propaganda/publicidade para $5,9 \%$ dos participantes neste estudo; apenas $2 \%$ dos inquiridos a consideram uma despesa sem garantia de retorno.

Com este trabalho procuramos também perceber quais as formas de comunicação e os meios que as microempresas e PME consideram mais eficazes. Os resultados demonstram que as empresas indicam a internet como um meio de comunicação e divulgação de excelência. E, como defende Pacheco (2008), “A internet é o meio que, a nível 
internacional, tem vindo a registar os maiores níveis de crescimento em investimento publicitário" e é o que mais margem tem para crescer nos próximos anos. Ao permitir a segmentação da oferta e da comunicação, a internet surge como o meio mais eficaz (e barato), pelo que muitas vezes é considerado um meio de comunicação low-cost. E os resultados obtidos neste estudo corroboram esta ideia, na medida em que as campanhas de publicidade a partir de cinquenta euros são o segundo cenário mais votado, traduzindo a imagem a que os inquiridos associam a comunicação low-cost, logo atrás de criatividade a preços convidativos. A rádio e a televisão são os meios considerados menos eficazes pelas microempresas e pelas PME nacionais.

De referir que o serviço integrado de comunicação - que contempla um pacote com a estratégia, a gestão do projecto e a produção e que Payet e Correa (2000) designam de full service shop - a par da criação são os serviços mais valorizados pelas microempresas e PME nacionais. Pelo resultado da amostra, quase assistimos a uma dicotomia: as empresas ou pretendem apenas o core business (criação) ou desejam uma solução integrada de comunicação.

A consultoria e os serviços especializados, logo seguidos da qualidade do trabalho produzido são as vantagens que as empresas indicam em trabalhar com agências. Por isso, a necessidade de realizar um vídeo ou um site são os motivos que fariam as empresas que não trabalham com agências recorrerem aos seus serviços. São dados a reter pelas agências de comunicação no seu portefólio de serviços e como argumentos para gerar new business.

Em contraponto, a monitorização das campanhas, maioritariamente realizada nas próprias empresas, é dos serviços menos valorizados pelos inquiridos.

Não obstante o contributo de Cagley (1986) que afirma que o factor humano é muito relevante na escolha de uma agência de comunicação e dos testemunhos que recolhemos nas entrevistas exploratórias realizadas no âmbito desta pesquisa - que indicavam a confiança depositada nos interlocutores da agência e no trabalho realizado como os aspectos mais valorizados num processo de selecção de uma agência -, a qualidade foi o factor que melhor cotação recebeu. Isto apesar de todos os outros aspectos indicados - referências de clientes satisfeitos, o relacionamento com os recursos humanos, a reputação da agência, serviços/tecnologia disponibilizados e o preço - serem considerados importantes.

Quanto à localização das agências, um tema abordado neste estudo, especialmente no que respeita à estratégia das agências low-cost para sustentarem esse posicionamento, os resultados demonstram que este factor é considerado menos relevante pelas empresas. Assim, confirma-se a hipótese 5: a localização não é um factor determinante para a selecção de uma agência. Ainda assim, os resultados demonstram que a localização é um factor mais valorizado pelas empresas que não trabalham com agências. Outro aspecto a reter nas acções de new business.

Como já havíamos referido anteriormente, a criatividade é outro factor crucial na relação cliente-agência e um dos motivos para a fazer prolongar. A comprovar a importância da criação/criatividade, os resultados demonstram que a ausência dela é um dos 
motivos que as empresas mais indicam para justificar a ruptura da relação com a agência. Curiosamente, e desconfirmando o que defendem alguns dos autores referenciados na revisão da literatura, o factor menos valorizado pelas empresas nacionais é o custo dos serviços da agência.

No que se refere aos meios, os resultados da nossa amostra demonstram que as empresas portuguesas escolhem racionalmente os suportes de comunicação para divulgação das suas campanhas, valorizando o público-alvo do meio e a notoriedade do mesmo. A gestão da imagem parece-nos, assim, no bom caminho, até porque grande parte dos inquiridos encara a comunicação como um investimento necessário e uma estratégia para ganhar notoriedade. Por isso, a escolha do meio certo para veicular a informação da empresa é um aspecto de elevada relevância, especialmente quando os constrangimentos financeiros tornam os recursos ainda mais escassos.

Quanto à primeira hipótese que equacionámos, os resultados confirmam que a crise altera a forma como as empresas encaram a comunicação e os seus investimentos. Os inquiridos atribuem uma menor importância à comunicação para (1) aumentar as vendas, (2) aumentar a notoriedade da marca e (3) apresentar novos produtos. Assim, parece-nos que a conjuntura acaba por relativizar a importância da comunicação, mas ressalva a consciência do papel estratégico da comunicação em contextos adversos, na medida em que os inquiridos afirmam que as empresas escolhem novos meios para divulgarem os seus produtos/serviços. Os meios de comunicação, particularmente os que são considerados low-cost, surgem, por isso, como soluções ainda mais pertinentes neste contexto.

Assim, a hipótese alternativa que equacionámos (H1a) - a crise leva as empresas a cortarem nos investimentos em comunicação - não se confirma.

Neste contexto, temos evidências estatísticas para afirmar que as empresas que não trabalham com agências consideram que, em tempo de crise, as campanhas de comunicação são importantes para a empresa se diferenciar da sua concorrência. Resultados que vão ao encontro do que defende Oliveira (2008), que afirma que "é necessário haver diferenciação dos concorrentes, investindo na apresentação de coisas novas", não obstante a crise que parece afectar todos os sectores de actividade. Esta evidência, na nossa opinião, corrobora uma outra hipótese (H2) que avançámos, a de que as empresas que não trabalham com agências têm uma imagem mais positiva do mercado da comunicação, em particular daquelas. As correlações demonstram ainda que quanto melhor opinião os interlocutores têm das agências, mais atenção exigem e mais referem a falta de atenção do gestor comercial como um motivo para terminar a relação de trabalho com uma agência.

Simon (1997) defende que as pequenas empresas têm maior apetência para reduzirem os preços e aumentarem a publicidade do que as grandes. E os resultados obtidos vão nesse sentido, revelando que perto de $30 \%$ dos inquiridos afirmam que com a crise a empresa não altera nada e cerca de $10 \%$ garantem mesmo que aumentam os investimentos em comunicação.

Os dados recolhidos demonstram que a maioria das empresas inquiridas $(64,7 \%)$ não trabalha com nenhuma agência. Como motivo para não trabalharem com agências, 
$34,3 \%$ dos inquiridos apontam a existência de um departamento próprio ou similar na empresa.

Quando inquiridos sobre que motivos os fariam recorrer aos serviços de uma agência, 36,4\% dos inquiridos apontam a necessidade de fazer um vídeo e 33,3\% indicam o site. Resultados compreensíveis, na medida em que estes suportes exigem conhecimentos técnicos específicos.

No que se refere às vantagens encontradas pelo facto de se trabalhar com agências, a consultoria/assessoria prestada e a equipa multidisciplinar que possuem estão entre os factores mais valorizados pelos participantes neste estudo (ambos com 33,3\% das respostas) que, logo de seguida, identificam a qualidade do trabalho realizado como uma mais-valia (23,5\% dos inquiridos).

Quanto ao conhecimento do conceito de comunicação low-cost, prolifera o desconhecimento quanto à sua existência (resposta dada por quase metade dos respondentes); em relação aos outros, os inquiridos que dizem haver comunicação low-cost em Portugal são em maior número. No que respeita ao low-cost e à imagem a ele associada, este conceito tem uma conotação positiva, na medida em que grande parte dos respondentes o associa a criatividade a preços convidativos. E é precisamente esta simbiose entre o preço e a qualidade que explica a afirmação deste conceito.

Com as respostas obtidas, analisámos a sensibilidade dos inquiridos ao preço e concluímos que este é, de facto, determinante: 39,2\% consideram que o preço teria de ser $40 \%$ inferior e $27,5 \%$ indicam entre $30 \%$ e $40 \%$ inferior ao das agências tradicionais para justificar a mudança para uma agência low-cost. 15,7\% afirmam que mudariam por um preço até $30 \%$ inferior, enquanto $17,6 \%$ dos inquiridos se mostraram irredutíveis a uma mudança para uma agência com este posicionamento.

Constatamos que as agências com posicionamento low-cost não parecem seduzir muito as empresas portuguesas. $41,2 \%$ dos inquiridos revelam ter alguma receptividade a trabalhar com este tipo de agências - parece-nos que dependente da atractividade do preço - face ao considerável número dos inquiridos que demonstram ter pouca ou nenhuma vontade de trabalhar com uma agência de baixo custo.

Os resultados demonstram ainda que à medida que aumenta a antiguidade na empresa diminui a receptividade às agências low-cost.

\section{Conclusões}

Neste estudo questionámos os inquiridos sobre a imagem que as empresas têm das agências de comunicação em Portugal e os resultados indicam que é positiva. As que trabalham com agências consideram-se satisfeitas com o seu trabalho. Com este pressuposto e a opinião de Rust e Oliver (2000, cit. in Caceres e Paparoidamis 2007), para quem a qualidade é uma das dimensões em que se baseia a satisfação, podemos inferir que as agências que actuam em Portugal têm qualidade. Uma opinião que é partilhada não só pelas microempresas e PME nacionais, mas também pelos grandes anunciantes, como tivemos oportunidade de comprovar pelos depoimentos recolhidos nas entrevistas exploratórias. 
Ao nível da estratégia, podemos concluir que existem diferenças de perspectiva entre os grandes anunciantes e as microempresas e PME. Os primeiros trabalham com agências, normalmente com mais do que uma, estabelecendo relações de parceria e contando com as agências para o planeamento estratégico da marca. Quanto às empresas mais pequenas, apesar de reconhecerem a qualidade do trabalho produzido por agências, afirmam não trabalhar com estas porque têm uma pessoa/departamento responsável pelas questões de marketing e/ou comunicação. Apesar disso, os serviços de consultoria/ assessoria são os mais valorizados pelas empresas nacionais.

Não obstante a importância do relacionamento com os recursos humanos da agência, os resultados demonstram que este não assenta necessariamente em relações de proximidade geográfica. Assim, a localização fora dos grandes centros urbanos pode ser um factor a explorar pelas agências para reduzirem os seus custos. Esta estratégia já vem sendo adoptada por algumas agências que assumem um posicionamento low-cost, mas não só, e é, em grande medida, justificada pelas potencialidades proporcionadas pela tecnologia, que fazem, por exemplo, com que as deslocações para uma reunião sejam cada vez menos frequentes.

A par do crescimento da tecnologia assiste-se a uma diminuição constante dos valores dos planos de marketing, o que exige investimentos cirúrgicos e proporciona a expansão crescente do marketing digital. Como referem Gaggi e Narduzzi (2006: 65), "a inovação técnica actualiza e aumenta continuamente a possibilidade de oferecer serviços originais aos consumidores low-cost”.

Apesar da indiscutível importância da internet e das suas potencialidades, ainda há um grande desconhecimento quanto à forma de optimizar este meio e de gerir eficazmente a comunicação das marcas com os seus públicos. Não obstante a adesão massiva das empresas portuguesas às redes sociais como o Facebook ou o Twitter, serão ainda poucas as que conseguem optimizar a rede de contactos que daí advém, extraindo informação útil para a segmentação dos seus públicos.

Apesar de associarem a comunicação low-cost a campanhas e criatividade a baixo custo, os inquiridos afirmam não saber se existe comunicação low-cost em Portugal. Mas esse aspecto pouco lhes parece importar, já que se mostram pouco receptivos às agências que adoptam este posicionamento. E nem a crise parece refrear esta tendência. Contudo, pelas evidências que fomos apresentando ao longo deste trabalho, consideramos que existe um mercado de comunicação low-cost em Portugal e este ganha forma através não só das agências que preconizam este posicionamento, mas também das outras. Para tal contribuem uma série de ferramentas e soluções de comunicação de baixo custo que podem ser propostas por agências ou por outro tipo de empresas que actuam a montante e a jusante, nomeadamente empresas de tecnologias de informação, bancos de imagens, gráficas, etc. Grande parte delas preconiza soluções para comunicação com recurso essencialmente a meios digitais.

Concluímos que o comportamento de compra das empresas portuguesas de maior dimensão se enquadra no perfil do consumidor low-cost, na medida em que aquelas conjugam parcerias e soluções de valor acrescentado com outras nas quais o preço é 
a mais-valia. Mas as decisões e a estratégia de comunicação continuam confiadas às agências de referência e assentam em relações de parceria duradoiras.

Ao contrário do que se poderia supor, os inquiridos não se mostram muito receptivos às agências de comunicação low-cost. O preço surge como o grande atractivo, mas ainda assim é significativo o número de inquiridos que afirma ter pouca ou nenhuma vontade de trabalhar com uma agência que adopte este posicionamento. E nem a crise parece alterar este facto. Aparentemente as empresas não associam às agências low-cost o mesmo nível de qualidade das agências tradicionais. O facto de estarem pouco receptivas às agências low-cost demonstra que a conjuntura económica desfavorável não dita novas regras. Assim, não se perspectiva um futuro muito risonho para as agências de comunicação em Portugal, particularmente quando o país enveredar no ciclo da retoma. Pelo que, com estes resultados, consideramos que a comunicação low-cost em Portugal é sinónimo de desinvestimento.

Concluímos também que em Portugal assistimos ao primado da qualidade, que permanece imune à conjuntura e constrangimentos financeiros. E estes resultados não são tão incongruentes quanto podem parecer à primeira vista, na medida em que este estudo revelou que mais de metade dos inquiridos considera que o que mais contribui para vender o produto/serviço da empresa é o próprio produto ou serviço, seguido do preço e só depois da comunicação.

Pelo exposto, constatamos que o conceito low-cost não é um argumento importante para grande parte das empresas portuguesas seleccionar a agência com que pretende trabalhar. Mas este posicionamento também não parece ampliar o leque de potenciais clientes, contribuindo para a democratização que alguns atribuem a este conceito. $\mathrm{O}$ facto de as empresas estarem pouco receptivas às agências low-cost demonstra que a conjuntura económica desfavorável não dita novas regras.

Assim, e tal como constatam Gaggi e Narduzzi (2006: 165), a Europa - e os seus cidadãos, que são dos que mais usufruem das vantagens deste conceito - encontra-se "menos preparada para enfrentar as solicitações produzidas pela emergência de uma sociedade mundial low-cost". O low-cost oprime tanto quanto democratiza, que o digam os profissionais da comunicação, particularmente na actual conjuntura. São essencialmente jovens a quem se lhes exige muita criatividade e inovação por "tostões"; por isso, e como defendem Gaggi e Narduzzi (2006: 166): “A sociedade low-cost é já uma realidade, mas é um modelo incompleto, incapaz de ver o homem na sua integridade e complexidade. O capitalismo selvático e os sistemas economicamente dinâmicos mas não democráticos não poderão, com certeza, curar-lhe as patologias. Esta nova realidade social necessita, pois, de humanização, valor plurissecular da identidade ocidental. O neo-humanismo da sociedade low-cost".

Este estudo apresenta dados curiosos, na medida em que não vão ao encontro dos resultados expectáveis. Demonstram que, ao contrário do que sucede noutras áreas moda, hotelaria e decoração -, a pertinência e o futuro do conceito low-cost aplicado ao mercado da comunicação parecem pouco auspiciosos, também pelas suas implicações humanas e sociais. É o reverso da medalha. 
Assim, parece-nos que podemos afirmar que o tempo (para conhecimento, e relacionamento, tanto profissional como pessoal) surge como uma variável determinante na actual sociedade. E a falta dele poderá explicar, pelo menos parcialmente, a não-afirmação do conceito low-cost no domínio da comunicação.

Pelo exposto, consideramos que este tema impõe necessariamente uma reflexão profunda ao nível das ciências sociais e que são necessárias pesquisas adicionais para validar, completar e ampliar os resultados actuais.

\section{Contributos}

A conceptualização e a medição das percepções da qualidade do serviço são dois dos mais debatidos e controversos tópicos da literatura de marketing. Apesar da existência de alguns estudos no contexto Business-to-Business - Woo e Ennew, 2004, 2005; bem como Caceres e Paparoidamis, 2004 cit. in Caceres e Paparoidamis (2007) -, esta é ainda uma área pouco explorada. Esta falta de definição produziu premissas que não foram resolvidas no que respeita à conceptualização e medição da percepção da qualidade do serviço e do seu impacto na satisfação, aspectos abordados no trabalho de Caceres e Paparoidamis (2007) e neste estudo.

Ao analisar e reflectir sobre alguns dos aspectos que foram alvo de reflexão de investigadores que analisaram o processo de selecção de agências, na perspectiva do cliente (Doyle et al., 1980; Cagley e Roberts, 1984; Cagley, 1986; Wackman et al., 1987; Harvey e Rupert, 1988; Verbeke, 1988; Dowling, 1994; Marshall e Na, 1994), bem como trabalhos que analisam a perspectiva da agência (Cagley, 1986; Fam e Waller, 1999; Caceres e Paparoidamis, 2005) e outros que examinam actividades específicas desenvolvidas pelas agências (Butkys e Herpel, 1992; Wills, 1992; Waller et al., 2001)1, este trabalho cruza aspectos abordados anteriormente na literatura e faz um levantamento que esboça um primeiro retrato da realidade portuguesa. Testa também um conceito (low-cost) aplicado a uma área específica (comunicação).

Numa conjuntura adversa como a que atravessamos e que tem grandes repercussões em sectores que implicam investimento, nomeadamente na comunicação, os responsáveis das agências precisam de definir claramente o desenvolvimento de estratégias de relacionamento, a sua oferta e as políticas de prestação de serviços. Como defende Lace (1998), o sucesso da relação agência-cliente depende, em grande parte, da capacidade das agências de comunicação em perceber e satisfazer as necessidades dos seus clientes. Para Caceres e Paparoidamis (2007), qualquer estudo de serviço e de satisfação com o relacionamento deve ter em conta a sua natureza dinâmica, pelo que este estudo e o teste ao conceito low-cost aplicado ao mercado da comunicação pareceu-nos particularmente oportuno numa conjuntura adversa como a actual.

Assim, este trabalho - que integra os conceitos de serviço, avaliação da satisfação e receptividade ao conceito - surge como a primeira tentativa de fornecer evidências 
empíricas sobre o conceito low-cost aplicado ao mercado da comunicação, tendo em conta uma variável conjuntural: o actual contexto de crise.

Também por isso, entendemos que as agências podem ter na produção e manutenção de conteúdos para os sites uma solução que permite o estabelecimento de avenças capazes de gerar encaixe financeiro contínuo e que podem funcionar como autênticos pacotes de fidelização. Cabe-lhes agora descobrir a melhor forma de garantirem este tipo de serviços. Ao longo deste trabalho apresentámos alguns exemplos de soluções, algumas em parceria, adoptadas por diferentes agências.

Apesar da indiscutível importância da internet e das suas potencialidades, ainda há um grande desconhecimento quanto à forma de optimizar este meio e de gerir eficazmente a comunicação das marcas com os seus públicos. Não obstante a adesão massiva das empresas portuguesas às redes sociais como o Facebook ou o Twitter, serão ainda poucas as que conseguem optimizar a rede de contactos e daí extrair informação útil para a segmentação dos seus públicos. O vazio legal e considerações de ordem ética em alguns domínios do marketing electrónico trazem preocupações acrescidas.

A obtenção de dados a partir da auscultação directa da realidade é determinante para o grau de novidade desta investigação e traduz uma das mais-valias deste trabalho, na medida em que, teoricamente, aumenta o seu interesse para a comunidade científica.

Os aspectos abordados neste estudo permitem, por isso, repensar as estratégias das agências, em especial no que se refere às acções de new business, contribuindo ainda para conhecer a imagem do mercado da comunicação em Portugal.

Do ponto de vista estratégico, este estudo apresenta conclusões de potencial interesse para as agências explorarem no desenvolvimento de estratégias de relacionamento, reflexão sobre a sua oferta e posicionamento, bem como de apresentação/realinhamento da sua vantagem competitiva. Esperamos que esta pesquisa contribua para que as agências sejam mais proactivas e focadas na melhoria da prestação dos serviços que apresentam ao mercado.

\section{Limitações}

Para recolha dos dados primários utilizámos um inquérito por amostragem não probabilística. Este método introduz as primeiras limitações em relação à exactidão dos resultados, na medida em que o erro da amostra não pode ser calculado.

Quanto ao tamanho da amostra, apesar de preencher os requisitos mínimos exigidos, ficou aquém das nossas expectativas e, na nossa opinião, seria um aspecto passível de melhoria, na medida em que contribui para evitar os erros aleatórios e melhorar a sua representatividade. Assim, são necessárias pesquisas adicionais para validar, completar e ampliar os resultados actuais.

\section{Sugestões de pesquisa}

Em termos gerais, a pesquisa deve dar continuidade à dialéctica das relações agência-cliente que envolve múltiplos factores e perspectivas. Tendo em consideração as con- 
clusões deste trabalho e as mudanças impostas pela actual conjuntura, que torna os mercados ainda mais mutáveis, deixamos aqui algumas sugestões para futuras pesquisas. Algumas delas são apresentadas numa perspectiva de complementaridade face ao presente trabalho.

Marketing digital é sinónimo de comunicação low-cost? Um estudo que poderá aferir e explorar melhor as potencialidades destes meios de comunicação.

Marketing electrónico: meios low-cost, que futuro? Passado este ciclo económico negativo, que perspectivas se vislumbram para estas soluções? Assistiremos à afirmação do paradigma electrónico?

Suportes de comunicação digitais: uma tendência eco(nómica)? Os suportes digitais irão impor-se como um suporte privilegiado do marketing "verde"? O ecomarketing será uma filosofia emergente ou antes uma resposta económica face à conjuntura? Que argumento vence no duelo economia versus ecologia?

Suportes de comunicação low-cost: vantagens e inconvenientes. Os suportes de comunicação de baixo custo vieram para ficar? Que credibilidade merecem? Quais os prós e contras destes meios?

Redes sociais, uma nova forma de comunicação low-cost? Que retorno conseguem as empresas portuguesas? Meio de comunicação ou fonte de desinformação? Que gestão e recursos disponibilizam as empresas para garantir a sua presença nas redes? Redes sociais: mais-valias e/ou ameaças para as marcas? Como podem as marcas gerir a sua presença nas redes?

Outsourcing dos serviços de marketing e comunicação. Que futuro? A gestão externa dos serviços de marketing e comunicação, já repetida noutros domínios empresariais basta pensarmos nos serviços contabilísticos e na produção -, será uma solução viável para as PME?

Este estudo analisa a realidade portuguesa, mas tentar aprofundá-lo e até cruzá-lo com as realidades e resultados obtidos noutros países é outra via que nos parece de particular interesse.

\section{Bibliografia}

Berman, S. J., Battino, B.; Shipnuck, L.; Neus, A. (2009) 'The End of Advertising as We Know It'. D. Gerbarg (ed.), Television Goes Digital, Springer Science + Business Media, p. 29.

Caceres, R. C. e Paparoidamis, N. G. (2007) 'Service Quality, Relationship Satisfaction, Trust, Commitment and Business-to-Business Loyalty'. European Journal of Marketing, Vol. 41, N. ${ }^{\circ}$ 7/8, pp. 836-867.

Cagley, J. (1986) 'A Comparison of Advertising Agency Selection Factors: Advertiser and Agency Perceptions'. Journal of Advertising Research. Junho/Julho.

El-Murad, J. e West, D. (2003) 'Risk and Creativity in Advertising'. Journal of Marketing and Management, Vol. 19 , pp. 657-673.

Gaggi, M. e Narduzzi, E. (2006) Low-cost-O fim da classe média. Lisboa: Teorema.

Lace, J. (1998). 'Evaluating Advertising Agency Performance: Actions to Enhance the Client/Agency Relationship'. Vol. 21, N. ${ }^{\circ} 7 / 8$, pp. 47-59.

Lima, M. J. (2009) 'O consumo dos portugueses perante a crise'. Disponível em http://www.meiosepublicidade.pt/2009/06/17/o-consumo-dos-portugueses-perante-a-crise/ consultado em 30/06/2009. 
Lima, M. J. (2009) 'Ric\&Vier oferece marketing integrado low-cost'. Disponível em http://www.meiosepublicidade.pt/2009/02/20/ricvier-oferece-marketing-integrado-low-cost/, consultado em 05/05/2010.

Oliveira, H. (2008) ' $82 \%$ dos anunciantes estão satisfeitos com suas agências de propaganda'. Disponível em http://www.portaldapropaganda.com/marketing/2008/11/0005. Consultado em 28/05/2009.

Pacheco, F. (2008) 'O que vai mudar na comunicação em Portugal?' Disponível em http://www.meiosepublicidade.pt/2008/10/10/o-que-vai-mudar-na-comunicacao-em-portugal/, consultado em 29/10/2008 e 27/09/2009.

Payet, A. e Correa, D. (2000) 'El Papel del Publicitário Ante un Nuevo Contexto Tecnológico'. Revista Latina de Comunicación Social, Vol. 30. Disponível em http://www.ull.es/publicaciones/latina/ aa2000yen/141vadavid.html. Consultado em 21/01/2009.

Saint-Seine, S. (2007) 'Logan MCV Gets Low-Cost Marketing'. Automotive News Europe, Vol. 12, N. 5 , p. 6 .

Simon, J. L. (1997) 'Firm Size and Market Behavior: A Theory of Their Relationship'. Journal of Economic Behavior \& Organization, 33, pp. 107-120.

Yuksel, U. e Sutton-Brady, C. (2007) 'From Selection to Termination: An Investigation of Advertising Agency/ Client Relationships'. Journal of Business \& Economic Research, Vol. 5, N. ${ }^{\circ} 1$.

Waller, D. (2004) 'Developing an Account-Management Lifecycle for Advertising Agency-Client Relationships'. Marketing Intelligence \& Planning. Vol. 22, N. ${ }^{\circ}$, pp. 95-112.

Sites consultados

http://www.hotshop.pt

http://www.merinemarketing.com

http://www.onlinesempre.com

http://www.ine.pt

http://cesarpallares.wordpress.com/2008/09/28/hotshop-\%E2\%80\%93-um-novo-conceito-em-agencia-de-propaganda, acedido dia 24/09/2009

http://tsf.sapo.pt/Programas/programa.aspx?content_id=904112\&audio_id=1191052, acedido dia 26/03/ 2010

http://www.salinas.pt/node/2619, acedido dia 26/04/2010

http://www.agenciafinanceira.iol.pt/economia/iol/1072657-4058.html, acedido dia 26/10/2009

http//www.meiosepublicidade.pt/2009/02/19/purple-e-daydream-fundem-se/, acedido dias 07/10/2009 e $13 / 05 / 2010$

http://www.transportes-xxi.net/taereo/investigacao/lowcost, acedido dia 17/11/2008

http://boostalpha.blogspot.com/2008/09/cheap-andchic-o-low-cost-invade-tudo.html, acedido dia 17/11/2008 


\section{Apêndice 1}

\section{Guião de entrevista exploratória}

- A empresa é sócia da APAN? Qual o objectivo? Vantagens?

- Tem departamento de Comunicação e Imagem, Marketing ou similar?

- Caracterização do departamento: número de pessoas, competências/tarefas realizadas.

- Diferenças de budget para comunicação 2008-2009 e anos anteriores.

- Percentagem da facturação gasta em comunicação e publicidade.

- Meios/suportes de comunicação utilizados em comunicação/publicidade.

- Como é feita a distribuição do budget por cada meio?

- Qual a agência com que trabalha? (E anteriores). Há quanto tempo trabalham com a actual agência?

- Tipo de contrato existente: avença ou trabalhos esporádicos (sem contrato definido)?

- Factores que considera determinantes para selecção/mudança de agência:

- Referência de clientes satisfeitos

- Solicitação pessoal

- Qualificações dos colaboradores da agência

- Preço dos serviços (custo da agência)

- Idade (antiguidade) da agência

- Bom portefólio, em termos de prémios de criatividade

- Reputação da agência

- Agência que se encaixa com a actual estratégia de marketing do cliente

- Integração num grupo internacional

- Tamanho da agência

- Trabalhos em curso

- Portefólio de trabalhos

- Equipamento/tecnologia da agência

- Localização

- Outro. Qual?

- Identifique os interlocutores da empresa (cargos) no relacionamento com a agência.

- Monitorização das campanhas. Existe? Como é feita?

- Resultados/retorno obtido.

- Que imagem tem do mercado publicitário em Portugal?

- Que avaliação faz das agências de comunicação em Portugal?

- Considera que existe mercado para a comunicação low-cost? A que níveis/em que vertentes?

- Que vantagens e desvantagens consegue identificar para este posicionamento?

- Comentários acerca do conceito low-cost. 